\title{
Sistem Informasi Lowongan Kerja Berbasis Web Untuk Bursa Kerja Khusus (BKK) Sekolah Menengah Kejuruan (SMK) XYZ Kota Jombang
}

\author{
Titasari Rahmawati ${ }^{1 *}$, Ariel Kristianto ${ }^{2}$ \\ 1* Program Studi Sistem Informasi, Institut Informatika Indonesia Surabaya, Jawa Timur \\ ${ }^{2}$ Program Studi Teknik Komputer, Institut Informatika Indonesia Surabaya, Jawa Timur \\ Email: ${ }^{1 *}$ tita@ikado.ac.id, ${ }^{2}$ ariel@ikado.ac.id
}

(Naskah masuk: 28 April 2021, direvisi: 02 Mei 2021, diterima: 10 Mei 2021)

\begin{abstract}
Abstrak
Teknologi informasi berupa internet telah memasuki kehidupan rumah tangga, sekolah, institusi publik, maupun dunia bisnis. Kebutuhan akan adanya teknologi dan informasi telah mengubah pola hidup dan kinerja suatu institusi atau lembaga khususnya lembaga penyedia informasi lowongan kerja atau biasa disebut dengan Bursa Kerja Khusus (BKK). BKK di Sekolah Menengah Kejuruan (SMK) XYZ di Kota Jombang masih menggunakan cara manual dalam memberikan informasi lowongan kerja ke calon lulusan atau ke alumni. Informasi lowongan kerja dibagikan dengan sebuah link yang didistribusikan melalui Media Sosial Whatsapp. Link tersebut mengarah ke google form yang mengharuskan calon kandidat untuk mengisi data-data lamaran. Calon kandidat mengalami proses yang redundant dalam pengisian data lamaran misalnya profil, riwayat pendidikan, dan pengalaman pelamar. Hal tersebut menjadi tidak efektif baik bagi pelamar dan admin BKK. Dengan demikian dirancang suatu sistem informasi lowongan kerja berbasis web yang dapat menjadi media informasi lowongan kerja untuk calon pelamar. Sebelum sistem diimplementasikan ke sekolah, dilakukan 2 (dua) kali tahap uji coba sistem dengan pengguna. Uji coba yang dilakukan mendapat masukan dari pengguna dan menjadi bahan perbaikan. Selain kegiatan uji coba juga dilakukan kegiatan pelatihan dimana dari kegiatan pelatihan tersebut dapat disimpulkan bahwa admin BKK, calon lulusan dan juga pihak perusahaan dapat menggunakan sistem tersebut dengan baik dan memberikan dampak yang positif untuk sekolah. Admin BKK dan mitra penyedia lowongan kerja dapat dengan mudah menambahkan informasi lowongan yang tersedia, sehingga calon lulusan/pelamar dapat memantau informasi lowongan kerja secara langsung melalui website dan dapat melamar sesuai dengan kualifikasi yang sudah ditetapkan oleh mitra penyedia lowongan.
\end{abstract}

KATA KUnCI: LOWONGAN KERJA, BURSA KERJA KHUSUS, SEKOLAH MENENGAH KEJURUAN, PELAMAR, LAMARAN, SISTEM INFORMASI

\section{Web-Based Job Vacancy Information System for Special Job Exchanges (BKK) XYZ Vocational Schools (SMK) Jombang City}

Abstract

Information technology in the form of the internet has entered the life of households, schools, public institutions, and the business world. The need for technology and information has changed the lifestyle and performance of an institution or institution, especially an institution providing job vacancy information or commonly known as the Special Job Exchange (BKK). The BKK at the XYZ Vocational High School (SMK) in Jombang City still uses the manual method in providing job vacancies information to prospective graduates or to alumni. Job vacancy information is shared with a link that is distributed via Whatsapp Social Media. The link leads to a google form that requires prospective candidates to fill in application data. Prospective candidates experience a redundant process in filling out application data such as profiles, educational history, and applicant's experience. This becomes ineffective for both applicants and BKK admins. Thus designed a web-based job vacancy information system that can be a medium of job vacancy information for prospective applicants. Before the system is implemented in schools, there are 2 (two) stages of testing the system with users. The trials carried out received input from users and became material for improvement. In addition to trial activities, training activities were also carried out where from the training activities it could be concluded that the BKK admin, prospective graduates and also the company could use the system well and have a positive 
impact on schools. BKK admins and job vacancy partners can easily add information on available vacancies, so that prospective graduates/applicants can monitor job vacancies directly through the website and can apply according to the qualifications set by the vacancy provider partners.

KEYWORDS: JOB VACANCIES, BKK, SMK, GRADUATES, ALUMNI, INFORMATION SYSTEM, APPLICANTS, COMPANIESSS

\section{PENDAHULUAN}

Kemajuan teknologi memungkinkan terjadinya otomatisasi hampir di segala bidang. Teknologi dan pendekatan baru yang menggabungkan dunia fisik, digital, dan biologi secara fundamental akan mengubah pola hidup dan interaksi manusia [1]. Terlebih hampir semua perangkat yang digunakan manusia telah terhubung dengan internet. Internet merupakan jaringan global yang menghubungkan komputer-komputer seluruh dunia, dengan internet sebuah komputer bisa mengakses data yang terdapat pada komputer lain di benua yang berbeda [2]. Kebutuhan akan adanya teknologi dan informasi menjadi semakin pesat dalam berbagai bidang. Salah satunya dalam pencarian informasi tentang lowongan pekerjaan khususnya pada masa sekarang ini yaitu masa pandemi COVID-19. Selama pandemi COVID-19 perusahaan tidak banyak membuka lowongan pekerjaan. Perusahaan hanya membuka lowongan pada beberapa divisi. Sehingga para pelamar kerja harus tanggap akan informasi tersebut dan mengharuskan para pelamar untuk mencari opsi lowongan pekerjaan lainnya.

Kondisi yang sudah diuraikan di atas mengubah pola kerja para penyedia informasi lowongan pekerjaan untuk menyediakan media yang dapat memberikan informasi lowongan pekerjaan kepada calon atau kandidat pelamar. Selain itu pelamar masih menggunakan cara-cara konvensional dalam menemukan informasi lowongan kerja, pelamar harus datang ke perusahaan untuk melihat secara langsung lowongan yang tersedia di perusahaan tersebut [3]. Dengan adanya kebutuhan tersebut, perusahaan berupaya melakukan kerja sama dengan dunia pendidikan khususnya dengan pihak sekolah terutama Sekolah Menengah Kejuruan (SMK) untuk dapat menjadi penyalur calon lulusannya atau alumninya [4]. Dalam penerapannya, SMK biasanya telah membentuk suatu lembaga khusus yang dinamakan Bursa Kerja Khusus (BKK) yang memberikan pelayanan dan informasi mengenai lowongan pekerjaan [5]. Bursa Kerja Khusus adalah lembaga yang berada di Satuan Pendidikan Menengah, Pendidikan Tinggi dan Lembaga Pelatihan Kerja yang mempunyai fungsi untuk mempertemukan antara pencari kerja dengan pengguna kerja [6]. BKK dituntut agar dapat membuat dan menyusun rencana dalam menjalankan tugasnya sebagai organisasi, bertindak dalam pelaksanaan, mengawasi jalannya proses pelaksanaan dan melakukan peninjauan kembali atas proses yang telah dilakukan agar tujuan bursa kerja khusus tercapai dengan maksimal [7].

Informasi-informasi yang diberikan oleh BKK biasanya hanya berupa link yang diarahkan ke google form yang telah dibuat oleh masing-masing perusahaan yang membuka lowongan pekerjaan. Link tersebut biasanya dibagikan melalui akun whatsapp atau dimuat dalam papan pengumuman sekolah. Kondisi demikian mengharuskan pelamar mengisi data lamaran yang sama secara berulang-ulang ketika mengajukan lamaran ke beberapa perusahaan yang menyediakan lowongan. Hal tersebut menjadi tidak efektif baik bagi pelamar, admin BKK dan pihak industry penyedia lowongan. Dengan demikian, pengelolaan sistem informasi yang baik akan memberikan pengaruh langsung kepada kinerja suatu organisasi atau Lembaga Pendidikan [8].

Dengan memberikan pelatihan sistem informasi lowongan kerja berbasis web dapat memberikan informasi, pengetahuan dan skill baru kepada pihak sekolah. Pihak sekolah khususnya BKK yang sebelumnya masih menggunakan cara manual dalam membagikan informasi dapat dengan mudah mengelola data lowongan dan juga pihak perusahaan dapat membagikan informasi lowongan dengan mudah kepada pihak sekolah dan juga calon pelamar.

\section{METODE KEGIATAN}

Sebelum mengembangkan sistem informasi lowongan kerja berbasis web, tim pengabdian melakukan wawancara kepada pihak sekolah yang sebelumnya merupakan tempat dimana salah satu tim pernah mengabdi menjadi tenaga pengajar di SMK XYZ di kota Jombang. Tim pengabdian yaitu Titasari Rahmawati dibantu dengan 1 mahasiswa melakukan wawancara kepada pihak wakil kepala sekolah bidang kesiswaan. Dari hasil wawancara tersebut tim pengabdian mendapatkan kesimpulan bahwa Bursa Kerja Khusus (BKK) SMK XYZ sedang mengalami kesulitan dalam memberikan informasi lowongan kerja. Selain itu tim pengabdian yang lain melakukan wawancara dengan calon lulusan SMK XYZ bahwa banyak calon lulusan yang terlambat menerima informasi lowongan dikarenakan akun whatsapp sedang error atau tidak adanya koneksi internet. Hal tersebut menjadi pertimbangan tim pengabdian untuk melakukan wawancara secara langsung dengan bagian BKK. 


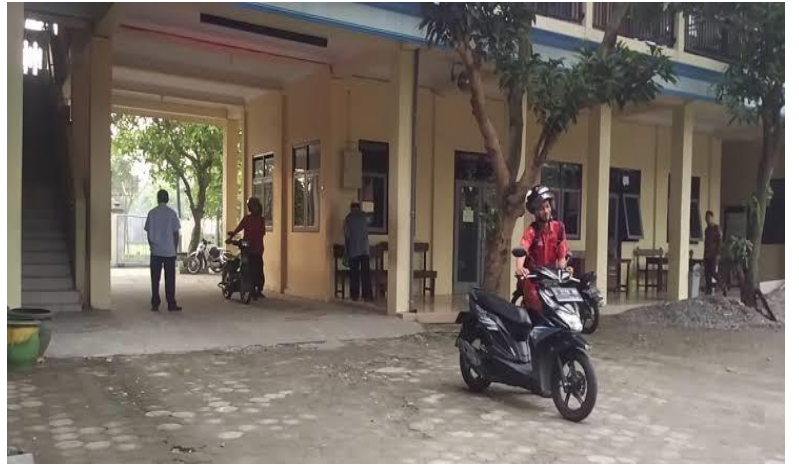

Gambar 1. Kegiatan Survey SMK XYZ Kab. Jombang

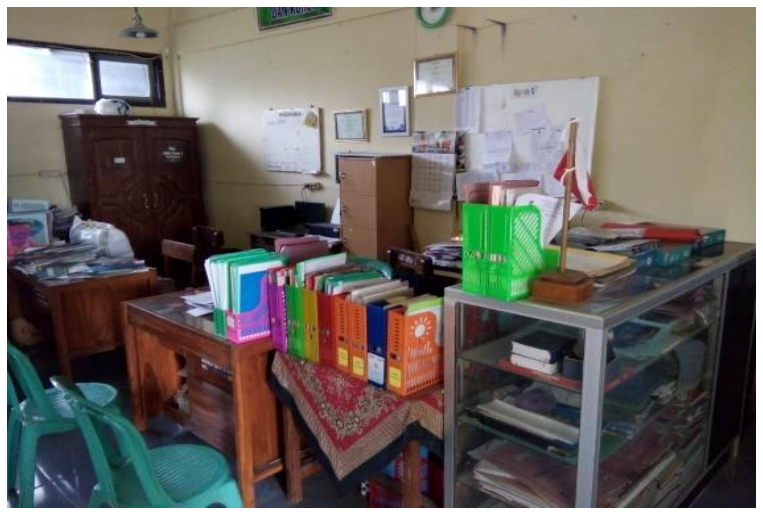

Gambar 2. Ruang Kerja BKK SMK XYZ Kab. Jombang

Kemudian tim pengabdian melakukan wawancara dengan bagian BKK. Bagian BKK memberikan informasi sama seperti informasi yang diberikan oleh wakil kepala sekolah bidang kesiswaan bahwa admin BKK kesulitan dalam mendistribusikan link pendaftaran tes dari perusahaan yang membuka lowongan kerja. Kemudian admin BKK juga kesulitan dalam melakukan pendataan calon lulusan, ada beberapa calon lulusan yang tidak memiliki akun Whatsapp.

Dari identifikasi masalah tersebut menjadi bahan yang dapat digunakan untuk menyusun kebutuhan sistem. Sebelum melakukan perancangan website, tim pengabdian yaitu Titasari Rahmawati dibantu dengan 1 mahasiswa memberikan sosialisasi pentingnya website sebagai media informasi program sekolah. Sehingga dengan adanya sosialisasi tersebut dapat memberikan pengetahuan kepada calon lulusan bahwa media website merupakan media yang praktis yang dapat diakses dimana saja dan kapan saja.

Pelaksanaan kegiatan pengabdian ini berlanjut dengan proses desain sistem dan implementasi sistem. Implementasi sistem dilakukan dengan tahap coding dimana dalam pembuatan sistem informasi ini menggunakan bahasa ASP.Net.

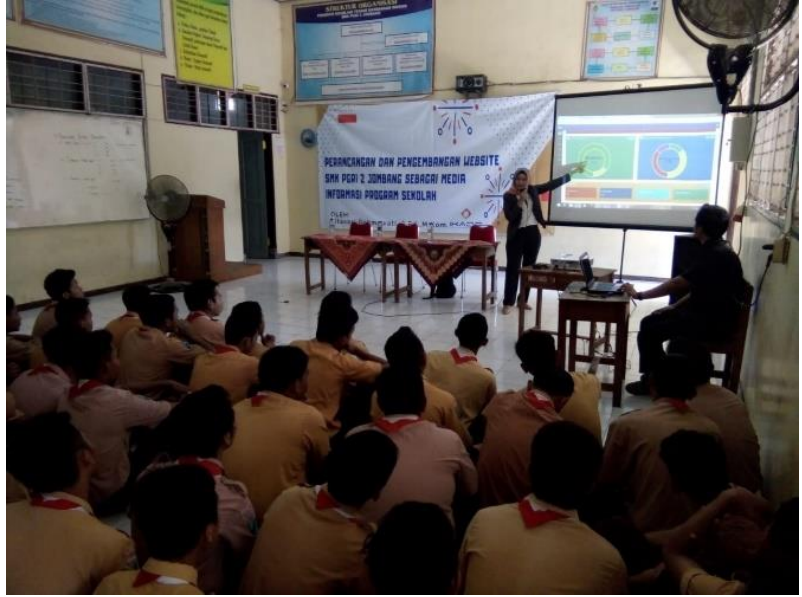

Gambar 3. Kegiatan Sosialisasi Pentingnya Website

ASP.Net dapat disusun dengan berbagai bahasa karena menyediakan kompatibilitas antar bahasa dan menyediakan model objek yang sangat banyak yang dapat digunakan oleh para pengembang [9]. Kemudian setelah tahap implementasi sistem dilanjutkan dengan tahap uji coba sistem. Pada saat tahap uji coba dilakukan dengan admin BKK dan 2 siswa sebagai calon lulusan. Pada saat tahap ujicoba, ketua tim pengabdian mengakses halaman website dengan disaksikan oleh mitra secara langsung, secara bersamaan admin BKK mengikuti arahan dari ketua untuk mengakses halaman website. Ketua menunjukkan website dari halaman utama, baik dengan hak akses admin, alumni maupun mitra (instansi). Admin BKK mengamati website dengan seksama dan admin BKK memberikan masukan tentang fitur website. Fitur website di halaman admin masih terdapat kekurangan yaitu admin harus membuat hak akses untuk alumni satu per satu. Hal tersebut kurang efektif karena akan menambah beban pekerjaan admin BKK. Kekurangan fitur tersebut akan direvisi setelah kegiatan uji coba. Setelah dilanjutkan dengan mengakses halaman-halaman selanjutnya pada website, admin BKK menemukan kolom-kolom yang tidak diperlukan dalam form pendaftaran yang terdapat pada hak akses alumni dan terdapat tambahan kolom isian berupa rata-rata nilai akhir serta kolom isian jurusan harus dinamis karena pelamar dapat berasal dari luar sekolah. Selain itu ditemukan juga data alumni yang sudah melamar, harus dibedakan dengan data siswa. Sehingga admin dapat mengetahui asal pelamar apakah dari luar sekolah atau bukan. Setelah ditemukan beberapa bug maka akan dilakukan revisi terkait bug-bug tersebut sehingga website dapat digunakan sesuai dengan harapan pengguna. 


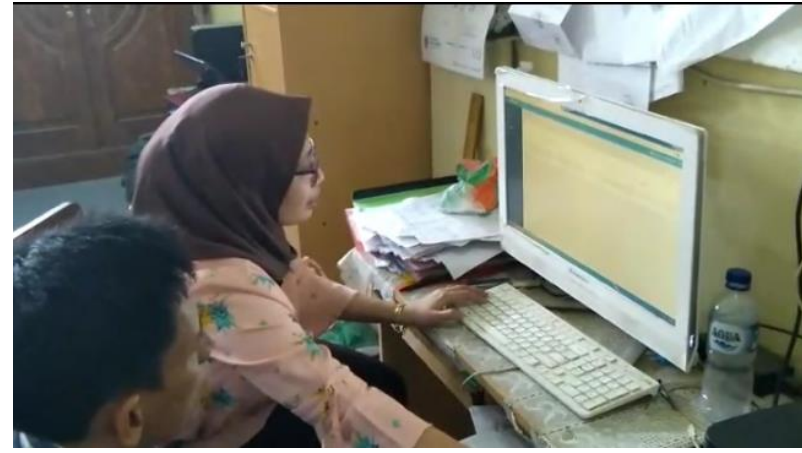

Gambar 4. Kegiatan Uji Coba Website dengan Staf BKK

Setelah kegiatan perbaikan sistem dilakukan kemudian diujicobakan kembali kepada staff BKK kemudian didapatkan hasil bahwa sistem dapat digunakan dengan baik dan tidak ditemukan bug sehingga kegiatan selanjutnya adalah pelatihan. Kegiatan pelatihan dilakukan dengan staf BKK dan calon lulusan. 4 calon lulusan mengikuti demonstrasi tim pengabdian dan calon lulusan yang lain menyimak kegiatan pelatihan.

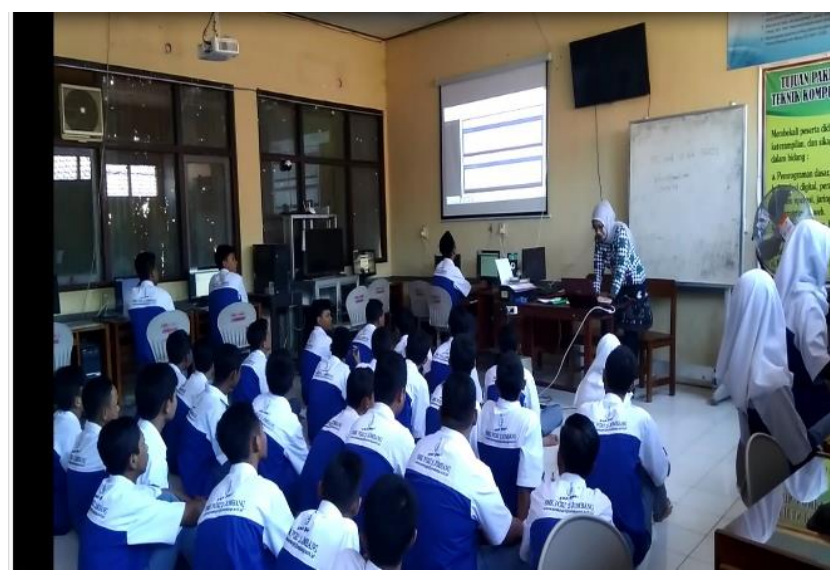

Gambar 5. Kegiatan Pelatihan dengan Calon Lulusan

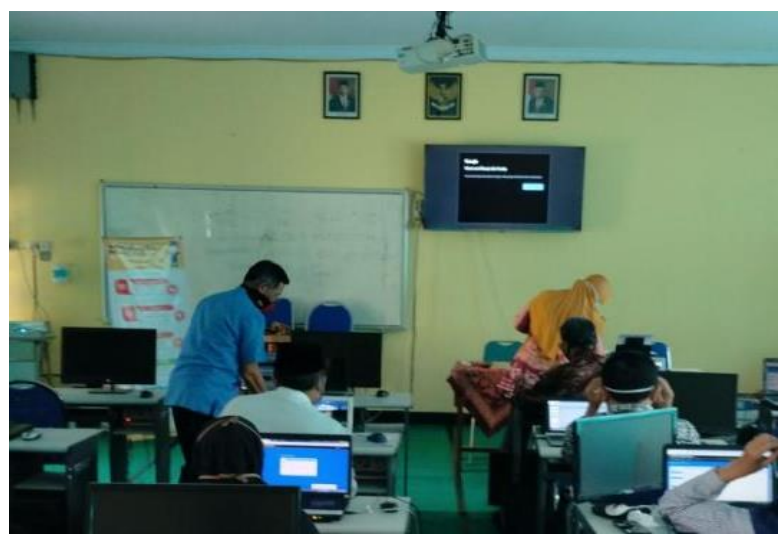

Gambar 5. Kegiatan Pelatihan dengan Calon Lulusan

\section{PELAKSANAAN KEGIATAN}

Pelaksanaan kegiatan pengabdian yang sudah dilakukan sampai saat ini adalah sistem telah diterapkan pada SMK XYZ khususnya pada unit BKK. Pada saat penyerahan sistem kepada unit BKK SMK XYZ tim pengabdian menyerahkan domain, hosting dan juga website untuk sepenuhnya dapat digunakan dalam menyelesaikan tugas unit BKK. Penyerahan tersebut diwakilkan oleh kepala unit BKK yaitu saudara Alimin Arianto, S.Pd.

Website yang diserahkan kepada pihak BKK SMK XYZ berisi halaman pengumuman, halaman admin BKK, halaman calon lulusan/pelamar, dan halaman admin industri/mitra. Pada sistem informasi lowongan kerja berbasis web ini dengan menggunakan hak akses admin maka akan ditampilkan submenu master yang berisi user untuk mengelola hak akses siswa dan mitra dan submenu mitra untuk mengelola data mitra kemudian lowongan serta lamaran.

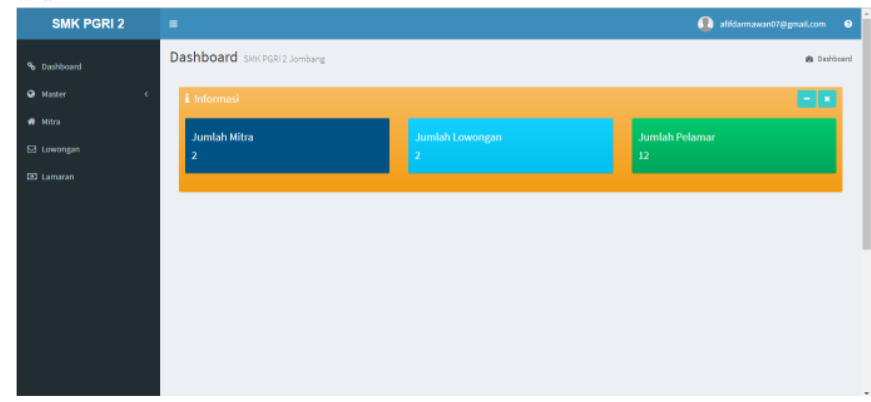

Gambar 6. Halaman Admin BKK

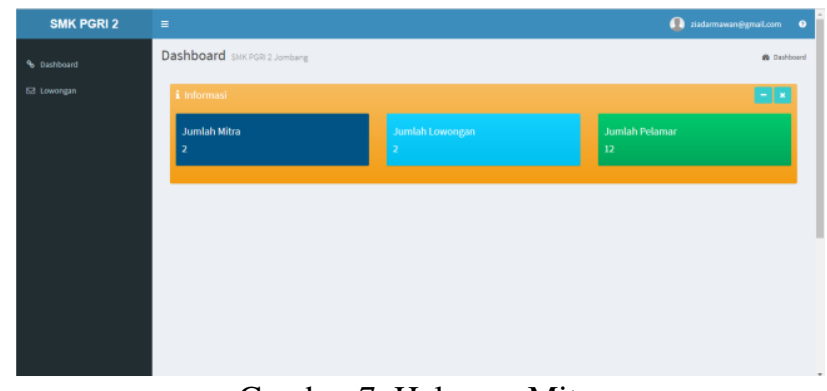

Gambar 7. Halaman Mitra

Alumni maupun bukan alumni SMK XYZ Jombang dapat melamar dengan cara mengisi form pendaftaran seperti pada gambar di bawah ini. Jika pelamar sudah melakukan pendaftaran kemudian jika ingin melamar pekerjaan pengguna cukup dengan sign in kemudian akan ditampilkan beberapa list lowongan pekerjaan yang up-to-date. 


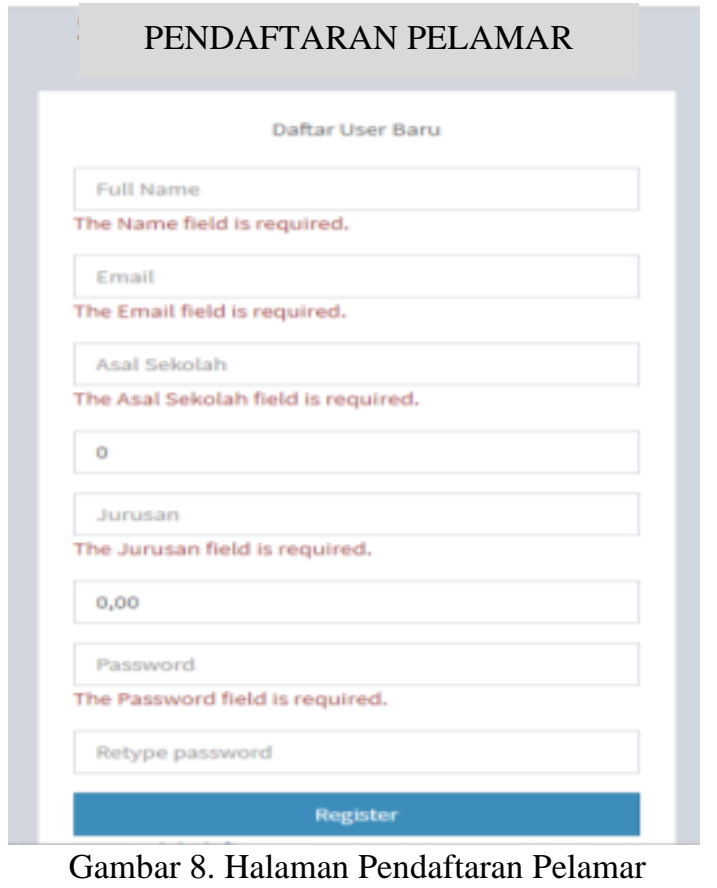

Jika pelamar sudah berhasil mendaftar (mengisi form pendaftaran) maka pelamar dapat melakukan sign in sehingga dalam halaman beranda akan tampil list lowongan yang terbaru. Pelamar cukup memilih lowongan apa yang akan dilamar kemudian menekan tombol lamar. Jika pelamar lolos kualifikasi oleh staf BKK maka pelamar akan mendapatkan email pemberitahuan.

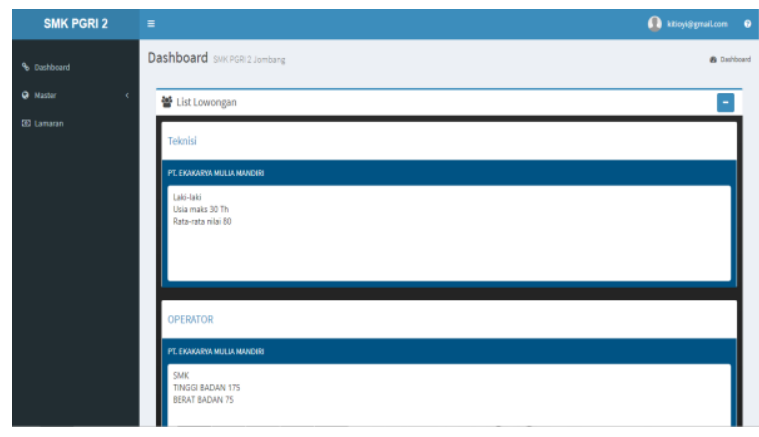

Gambar 9. Halaman Beranda Pelamar

Fitur-fitur yang terdapat pada sistem informasi lowongan kerja berbasis web telah dapat digunakan dengan baik berdasarkan hasil uji coba yang telah dilaksanakan tim pengabdian bersama dengan staf BKK. Selain itu penulis juga mendistribusikan kuesioner ke admin BKK untuk mendapatkan feedback dari program pengabdian yang sudah dilaksanakan. Dari 7 pertanyaan yang terdapat pada kuesioner terdapat 5 pertanyaan yang mendapatkan respon jawaban Sangat Setuju dan 2 pertanyaan mendapatkan respon Setuju. Dari hasil kuesioner tersebut dapat diambil kesimpulan bahwa program pengabdian yang dilaksanakan berjalan dengan baik dan produk yang dihasilkan dapat memberikan manfaat bagi sekolah khususnya BKK untuk membantu mengelola informasi lowongan kepada calon lulusan dan alumni. Keberlanjutan dari kegiatan pengabdian yang sudah dilaksanakan berupa maintenance sistem dan juga diharapkan tim pengabdian dapat berhubungan dengan baik dengan pihak sekolah jika nantinya ditemukan kendala khususnya terkait permasalahan teknis tentang sistem. Selain itu tim pengabdian juga telah mendapatkan pengalaman, pengetahuan dan wawasan baru khususnya tentang kerja sama tim, komunikasi dengan stakeholder, dan juga masalah-masalah teknis terkait sosialisasi dan pelatihan sistem.

\section{KESIMPULAN}

Keberlanjutan dari kegiatan pengabdian yang sudah dilaksanakan berupa maintenance sistem dan juga diharapkan tim pengabdian dapat berhubungan dengan baik dengan pihak sekolah jika nantinya ditemukan kendala khususnya terkait permasalahan teknis tentang sistem. Selain itu tim pengabdian juga telah mendapatkan pengalaman, pengetahuan dan wawasan baru khususnya tentang kerja sama tim, komunikasi dengan stakeholder, dan juga masalah-masalah teknis terkait sosialisasi dan pelatihan sistem.

\section{REFERENSI}

[1] Tjandrawina, R.R. (2016). Industri 4.0: Revolusi industri abad ini dan pengaruhnya pada bidang kesehatan dan bioteknologi. Jurnal Medicinus, Vol 29, Nomor 1, Edisi April

[2] Hidayatullah, dan Kawistara, 2015. Pemrograman Web. Bandung: Informatika

[3] M Safitri, A Novianti, A Noviriandini. 2018. Sistem Informasi Berbasis Web. Jurnal Pilar Nusa Mandiri Vol 14(1), 49-54

[4] Maiyana, E. (2017). Perancangan Aplikasi Media Informasi Lowongan Kerja Perusahaan Bagi Pencari Kerja Berbasis Web. Jurnal Sains dan Informatika. [Online], 3(12), hal. 118-125

[5] Rahmawati, T., \& Magh'firoh, R. H. (2019). Perancangan Website SMK PGRI 2 Jombang Sebagai Media Informasi Program Sekolah. Dharma Raflesia, 42-49.

[6] Depnakertrans RI. (2004). Keputusan Direktur Jenderal Pembinaan dan Penempatan Tenaga Kerja Dalam Negeri No.KEP-/131/DPPTKDN/XI/2004, tentang Petunjuk Teknis Bursa Kerja Khusus.

[7] Lukman, Mutaqin. (2018). Kinerja Bursa Kerja Khusus (Bkk) Smk Dalam Penyiapan Lulusannya Memasuki Dunia Kerja. E-Journal Universitas Negeri Yogyakarta Vol 8(4), 285-293

[8] Dyna Marisa Khairina, D. (2018). Sistem Informasi Manajemen Ruang (Simeru) Kelas (Studi Kasus: Fkti Universitas Mulawarman). Ilmiah Ilmu Komputer, 13(1), 3.
Retrieved 
http://ejournals.unmul.ac.id/index.php/JIM/article/view/1 023

[9] Indah, R.N. (2019). Alternatif Aplikasi Mudah Perpustakaan (Pengenalan Aplikasi ASP.Net). Jurnal Ilmu
Perpustakaan dan Informasi, (3), 1. diakses dari https://baitululum.fah.uinjambi.ac.id/

index.php/b_ulum/article/download/41/20 